\title{
Nonvalvular right atrial papillary fibroelastoma
}

\author{
Emad Uddin Hakemi, MD, ${ }^{\mathrm{a}}$ Jennifer Bero, MD, ${ }^{\mathrm{b}}$ Marin Sekosan, MD, ${ }^{\mathrm{b}}$ and Asimul Ansari, MD,${ }^{\mathrm{c}}$ Chicago, Ill
}

We present the case of a 61-year-old woman with a previous history of hypertension and diabetes mellitus. The patient was admitted for acute cholecystitis, which was confirmed radiologically by a computed tomography scan with contrast that also showed an incidental right atrial filling defect. A transthoracic echocardiogram showed a $20 \times 22-\mathrm{mm}$ spheric echogenic mass in the right atrium with mild mitral annular calcification. Surgical resection was planned using preoperative coronary angiography, which showed no evidence of coronary artery disease. She underwent surgical resection through a right atriotomy and a cardiopulmonary bypass without any adverse events. Grossly, the tumor was a $4 \times 3-\mathrm{cm}$, cauliflower-shaped, purple-colored mass attached to the interatrial septum (Figure 1). A bovine pericardial patch was used to repair the resultant defect. Histopathology showed numerous papillae with endocardial lining and cores containing myocytes as well as scattered elastic fibers (Figure 2). The postoperative period was complicated by an atypical atrial flutter that was treated medically.

\section{DISCUSSION}

An autopsy series showed an estimated incidence of $0.0017 \%$ to $0.33 \%$ of primary cardiac tumors; cardiac papillary fibroelastomas (CPFEs) represented only $8 \%$, making this diagnosis extremely rare. ${ }^{1,2}$ CPFEs represents $80 \%$ of all valvular cardiac tumors. ${ }^{3}$ Valvular CPFE represents $73 \%$ of reported cases of CPFE. Most nonvalvular CPFEs originate in the left ventricle, with only a few cases to our knowledge reported in the right atrium, as in our patient (Table 1). ${ }^{4-20}$

On reviewing the literature on nonvalvular right atrial CPFEs (Table 1), most cases were discovered incidentally during a cardiac work-up for unrelated symptoms or signs including transient ischemic attacks, syncope, or murmurs. Other cases were linked to recurrent pulmonary embolism. One case presented as recurrent Staphylococcus aureus

\footnotetext{
From the Departments of Internal Medicine, ${ }^{\mathrm{a}}$ Pathology, ${ }^{\mathrm{b}}$ and Cardiology, ${ }^{\mathrm{c}}$ John H. Stroger Hospital of Cook County, Chicago, Ill.

Disclosures: Authors have nothing to disclose with regard to commercial support.

Received for publication Jan 28, 2013; revisions received Feb 17, 2013; accepted for publication Feb 28, 2013; available ahead of print April 1, 2013.

Address for reprints: Emad Uddin Hakemi, MD, Department of Internal Medicine, John H Stroger Hospital of Cook County, 1901 W Harrison St, Chicago, IL

60612 (E-mail: e.hakmi@gmail.com).

J Thorac Cardiovasc Surg 2013;145:e71-3

$0022-5223 / \$ 36.00$

Copyright (c) 2013 by The American Association for Thoracic Surgery

http://dx.doi.org/10.1016/j.jtcvs.2013.02.077
}

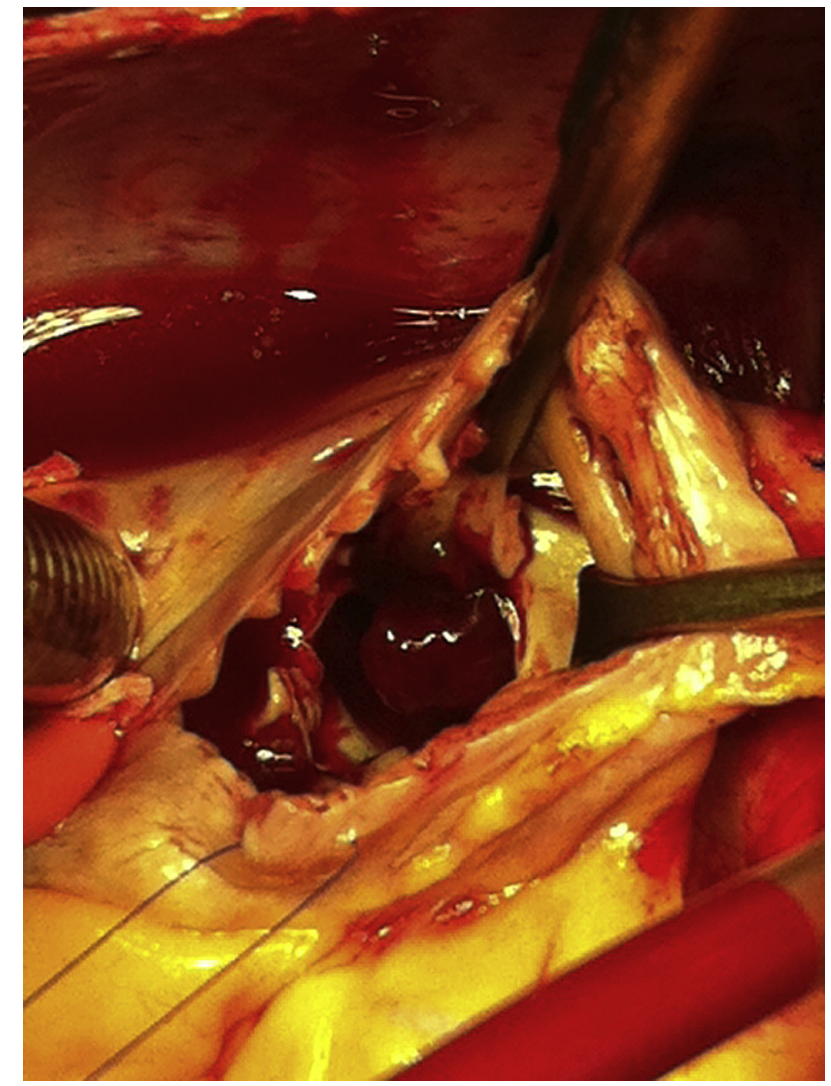

FIGURE 1. Surgical field showing the right atrial cardiac papillary fibroelastoma before resection.

bacteremia secondary to infected CPFEs growing on the right atrial Chiari formation. ${ }^{16}$ Right-sided CPFEs can present as a pulmonary embolism in $0.4 \%$ of all cases of CPFEs. $^{3}$

Physical examination of the patient might be significant for positional systolic and diastolic murmurs that can occur depending on the size, mobility, and location of the tumor. The diastolic tumor murmur was described in 1 case of CPFE to involve the tricuspid valve compared with $30 \%$ of cases of atrial myxomas. ${ }^{21}$ Our review showed 1 case of right-sided nonvalvular CPFE discovered during the work-up of an apical murmur. ${ }^{9}$

Transthoracic echocardiography, with an estimated sensitivity and specificity of $88.9 \%$ and $87.8 \%$, respectively, remains the most common initial test to detect CPFEs. For tumors smaller than $20 \mathrm{~mm}$, the reported transthoracic echocardiography sensitivity decreases to $61.9 \%$ compared with the more sensitive transesophageal echocardiography, which has a sensitivity of $76.6 \% .^{22}$ Good correlation 


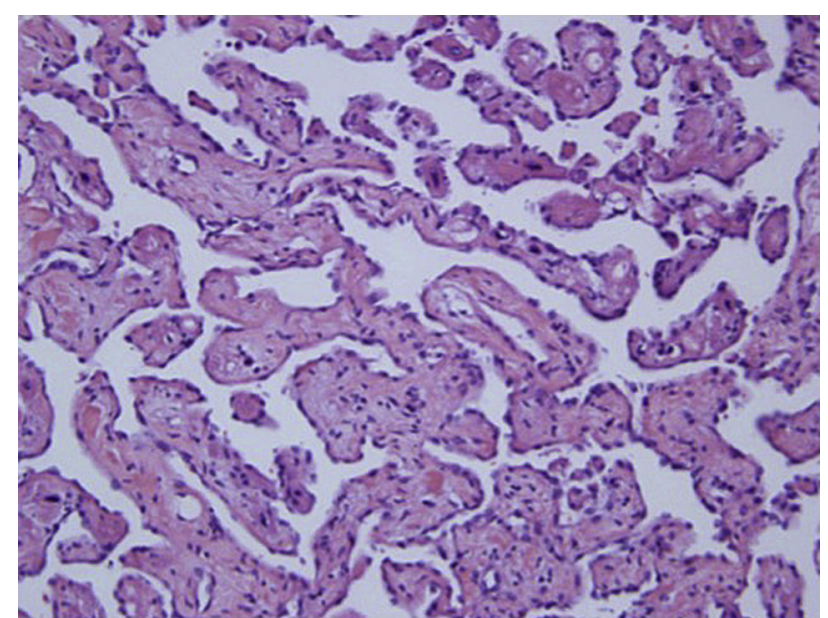

FIGURE 2. A high-power hematoxylin and eosin stain showing the collagenous cores lined by endothelial cells.

between echocardiography and pathologic size of the tumor has been reported $(\mathrm{r}=0.87 ; P<.001)$. Few cases of CPFE have been detected with computed tomography, as in our patient. ${ }^{15}$ Gadolinium-enhanced magnetic resonance imaging with enhancement of the periphery of the tumor secondary to trapping of the gadolinium in the fronds of collagen and elastin also has been described. ${ }^{23}$

Histopathology shows an avascular core of elastin and immature collagen fibers with a single layer of endocardium outlining the papillomatous-like tumor. ${ }^{24}$ After placing the tumor in water, sea anemone-like branches with multiple papillary fronds arising from a central stalk create its characteristic gross appearance. ${ }^{25}$ In our patient

TABLE 1. Case reports of nonvalvular right atrial papillary fibroelastoma

\begin{tabular}{|c|c|c|c|c|c|}
\hline Study & Year & Age, $y$ & Sex & Symptom & Size, $\mathbf{m m}$ \\
\hline Schiller et $\mathrm{al}^{4} *$ & 1970 & N/A & N/A & N/A & N/A \\
\hline Schwinger et $\mathrm{al}^{5}$ & 1989 & N/A & N/A & N/A & N/A \\
\hline Wasdahl et al ${ }^{6}$ & 1992 & 85 & Male & N/A & N/A \\
\hline Gallas et $\mathrm{al}^{7}$ & 1993 & 69 & Male & Incidental & $25 \times 20$ \\
\hline Crestanello et $\mathrm{al}^{8}$ & 2002 & 86 & Female & Syncope & 40 \\
\hline Singh et $\mathrm{al}^{9}$ & 2004 & 75 & Male & Murmur & $25 \times 25$ \\
\hline Hindupur et $\mathrm{al}^{10}$ & 2005 & N/A & N/A & N/A & N/A \\
\hline Nagano et al ${ }^{11}$ & 2005 & 68 & Female & Incidental & 20 \\
\hline Gabbieri et $\mathrm{al}^{12}$ & 2006 & 70 & Female & Recurrent PE & $10 \times 10$ \\
\hline Lotto et $\mathrm{al}^{13}$ & 2006 & 60 & Female & W/U of CAD & $20 \times 22$ \\
\hline Lauten et $\mathrm{al}^{14}$ & 2007 & 66 & Female & Incidental & $28 \times 25$ \\
\hline Kim et $\mathrm{al}^{15}$ & 2007 & 62 & Female & Incidental & N/A \\
\hline Latif et $\mathrm{al}^{16}$ & 2008 & 41 & Male & IEC & $12 \times 20$ \\
\hline Abad et $\mathrm{al}^{17}$ & 2008 & 60 & Male & W/U of TIA & $20 \times 15$ \\
\hline Maybury et $\mathrm{al}^{18}$ & 2009 & 74 & Male & Presyncope & $10 \times 10$ \\
\hline Nwiloh et al ${ }^{19}$ & 2011 & 73 & Male & W/U of TIA & $33 \times 30$ \\
\hline Marboeuf et $\mathrm{al}^{20}$ & 2012 & 65 & Male & $\mathrm{PE}$ & $30 \times 28$ \\
\hline
\end{tabular}

$N / A$, Not available; $W / U$, work up; $P E$, pulmonary embolism; $C A D$, coronary artery disease; IEC, infective endocarditis; TIA, transient ischemic attack. *This study reported 2 cases. we were able to identify numerous myocytes in the core of the papillomatous projections, which rarely has been reported.

All reported cases of right-sided CPFE have been managed with surgical resection with cardiopulmonary bypass except for 1 case managed through a minimally invasive right thoracotomy. ${ }^{15}$ Three cases had a concomitant coronary artery bypass graft with surgical resection of the right-sided CPFE. Recurrence after surgical resection has not been described in the literature even with prolonged follow-up periods of up to 114 months. ${ }^{17}$

\section{References}

1. Klarich KW, Enriquez-Sarano M, Gura GM, Edwards WD, Tajik AJ, Seward JB. Papillary fibroelastoma: echocardiographic characteristics for diagnosis and pathologic correlation. J Am Coll Cardiol. 1997;30:784-90.

2. Richard RW. Tumours of the heart. Review of the subject and report of one hundred fifty cases. Arch Pathol. 1951;51:98-128.

3. Gowda RM, Khan IA, Nair CK, Mehta NJ, Vasavada BC, Sacchi TJ. Cardiac papillary fibroelastoma: a comprehensive analysis of 725 cases. Am Heart J. 2003; 146:404-10.

4. Schiller AL, Schantz A. Papillary endocardial excrescence of the right atrium: report of two cases. Am J Clin Pathol. 1970;53:617-21.

5. Schwinger ME, Katz E, Rotterdam H, Slater J, Weiss EC, Kronzon I. Right atrial papillary fibroelastoma: diagnosis by transthoracic and transesophageal echocardiography and percutaneous transvenous biopsy. Am Heart J. 1989;118(5 Pt 1): 1047-50.

6. Wasdahl DA, Wasdahl WA, Edwards WD. Fibroelastic papilloma arising in a Chiari network. Clin Cardiol. 1992;15:45-7.

7. Gallas MT, Reardon MJ, Reardon PR, De Felice CA, Raizner AE, Mody DR. Papillary fibroelastoma. A right atrial presentation. Tex Heart Inst J. 1993;20: 293-5.

8. Crestanello JA, Orszulak TA. Giant papillary fibroelastoma of the right atrium: an unusual presentation. Ann Thorac Surg. 2002;74:1252-4.

9. Singh H, Alam M, Schwartz D, Martin JR. Right atrial papillary elastoma: an uncommon location. Echocardiography. 2004;21:273-4.

10. Hindupur S, Schwabe JL. Papillary fibroelastoma of the right atrium: an atypical presentation. A case report and review of the literature. J Cardiovasc Surg. 2005; 46:589-91.

11. Nagano H, Kawahito K, Kobinata T, Nakatani K, Osawa S, Adachi S, et al. Papillary fibroelastoma of the right atrium; report of a case [in Japanese]. Kyobu Geka. 2005;58:1003-5.

12. Gabbieri D, Rossi G, Barutti L, Corghi F, Zaca F, Sarandria D, et al. Papillary fibroelastoma of the right atrium as an unusual source of recurrent pulmonary embolism. J Cardiovasc Med. 2006;7:373-8.

13. Lotto AA, Earl UM, Owens WA. Right atrial mass: thrombus, myxoma, or cardiac papillary fibroelastoma? J Thorac Cardiovasc Surg. 2006;132: 159-60.

14. Lauten A, Strauch JT, Wipperman J, Walers T. A rare type of right tumor in a 66year-old woman. J Thorac Cardiovasc Surg. 2007;133:251-2.

15. Kim RW, Jeffery ME, Smith MJ, Rl Wilensky, Woo EY, Woo YJ. Minimally invasive resection of papillary fibroelastoma in a high-risk patient. $J$ Cardiovasc Med (Hagerstown). 2007;8:639-41.

16. Latif F, Peyton M, Laszik Z, Sivaram CA. Infective endocarditis of a papillary fibroelastoma on Chiari network of right atrium: a case report. J Am Soc Echocardiography. 2008;21:188.e3-4.

17. Abad C. De la Rosa P. Right atrial papillary fibroelastoma associated with atrial septal defect, persistent superior vena cava, and coronary artery disease. J Thorac Cardiovasc Surg. 2008;136:538.

18. Maybury R, Mullenix P, Greenberg M, Liu M, Trachiotis G. Rare anatomic location of a papillary fibroelastoma. Ann Thorac Surg. 2009;88:2034-5.

19. Nwiloh J, Hernandez E, Mercado A. Right atrial papillary fibroelastoma. J Card Surg. 2011;26:39-41.

20. Marboeuf P, Wautot F, Garot J, Juthier F, Vincentelli A, Ennezat PV, Maréchaux S. Echocardiographic, cardiac magnetic resonance imaging, surgical and pathological findings of an unusual right atrial tumor: a giant papillary fibroelastoma. Ann Thorac Surg. 2012;93:e133. 
21. Frumin H, O'Donnell L, Kerin NZ, Levine F, Nathan LE Jr, Klein SP. Two-dimensional echo- cardiographic detection and diagnostic features of tricuspid papillary fibroelastoma. J Am Coll Cardiol. 1983;2:1016-8.

22. Sun JP, Asher CR, Yang XS, Cheng GG, Scalia GM, Massed AG, et al. Clinical and echocardiographic characteristics of papillary fibroelastomas: a retrospective and prospective study in 162 patients. Circulation. 2001; 103:2687-93.
23. Atalay MK, Taner AT. Gradual enhancement of a large left atrial papillary fibroelastoma on cardiac magnetic resonance: the waiting game. Tex Heart Inst J. 2010; 37:612-3.

24. Burke A, Virmani R. Papillary fibroelastoma: tumors of the heart and great vessels. AFIP Atlas of Tumor Pathology. 1996;16:47-54.

25. Kim KH, Choi JB. Papillary fibroelastoma in tricuspid valve: an unusual cause of atypical chest pain. J Thorac Cardiovasc Surg. 2013;145:1131.

\title{
Surgical ablation of typical atrial flutter refractory to catheter ablation
}

\author{
Fei Lü, MD, PhD, FACC, FHRS, Taibo Chen, MD, Kenneth K. Liao, MD, PhD, FACS, and \\ David G. Benditt, MD, FACC, FRCPC, FHRS, Minneapolis, Minn
}

To our knowledge, surgical dissection of the cavotricuspid isthmus (CTI) for treatment of typical atrial flutter (AFL) has not been reported previously. A surgical approach, however, may be needed for catheter access for AFL ablation in patients with complex congenital structures with or without surgical repair, ${ }^{1}$ or for hybrid approach for atrial fibrillation ablation. ${ }^{2}$

\section{Case Report}

A 35-year-old man with a history of arrhythmogenic right ventricular cardiomyopathy (ARVC) and after implantation of an implantable cardioverter defibrillator (ICD) presented with recurrent symptomatic atrial tachycardias after 2 unsuccessful attempts of prolonged catheter ablation, reportedly for typical AFL and right atrial (RA) tachycardias at other facilities. On presentation to us, a surface electrocardiogram showed typical AFL morphology with a tachycardia cycle length (TCL) of $360 \mathrm{~ms}$ and a 2:1 atrioventricular conduction (Figure 1, top). The echocardiogram showed severely enlarged RA $(97 \mathrm{~mm})$ with mild tricuspid insufficiency and right ventricular (RV) enlargement $(76 \mathrm{~mm})$ with RV ejection fraction of approximately $10 \%$ and left ventricular ejection fraction of $55 \%$ to $60 \%$.

The patient underwent repeat electrophysiological study. An open-irrigation deflectable catheter with a 3.5-mm tip (ThermoCool; Biosense Webster, Inc, Diamond Bar, Calif) was used for mapping and radiofrequency ablation. Entrainment and a 3-dimensional activation map indicated that the

\footnotetext{
From the Cardiac Arrhythmia Center, Division of Cardiovascular Medicine, Department of Medicine, University of Minnesota Medical School, Minneapolis, Minn Disclosures: Authors have nothing to disclose with regard to commercial support. Received for publication Jan 4, 2013; revisions received Feb 19, 2013; accepted for publication March 4, 2013; available ahead of print April 8, 2013.

Address for reprints: Fei Lü, MD, PhD, FACC, FHRS, Cardiac Electrophysiology Laboratories, Department of Cardiovascular Medicine, University of Minnesota, MMC 508, 420 Delaware St SE, Minneapolis, MN 55455 (E-mail: luxxx074@ umn.edu).

J Thorac Cardiovasc Surg 2013;145:e73-5

$0022-5223 / \$ 36.00$

Copyright (C) 2013 by The American Association for Thoracic Surgery http://dx.doi.org/10.1016/j.jtcvs.2013.03.002
}

tachycardia was consistent with typical counterclockwise CTI-dependent AFL. The CTI was mapped carefully and systematically to search for any detectable atrial signals. Only at a more lateral location in the CTI were there detectable residual atrial signals, whereas there were no or minimal atrial signals at other sites along the whole CTI, presumably owing to the previous ablations. Radiofrequency ablation of the CTI at 7:30 o'clock position followed by ablations at 6:30, 5:30, and 5:00 o'clock position in the 50 left anterior oblique projection produced no effects on tachycardia. Subsequently, a very tiny ventricular signal (without detectable atrial signal) could be recorded at a location more medial toward the septum and more distal toward the tricuspid annulus (TA) and the right ventricle in the isthmus. An ablation lesion delivered to this site successfully terminated the tachycardia (Figure 1, bottom). Insurance burns were placed around the nearby area.

Postablation pacing from coronary sinus $5 / 6$ electrodes at a cycle length of $300 \mathrm{~ms}$ re-induced tachycardia with a TCL of $400 \mathrm{~ms}$. After counterclockwise CTI-dependent flutter again was confirmed by a repeat activation map, additional ablation lesions were delivered along the most medial ablation line crossing the previously successful ablation site in the isthmus. One of these ablations in the middle of the CTI along this line again successfully terminated the tachycardia despite the absence of significant atrial signals at either the distal or proximal poles of the ablation catheter. Afterward, there was no inducible tachycardia with or without isoproterenol. The patient was discharged home the following day with warfarin and carvedilol for his ARVC, without apparent complications.

Approximately 1 month after the last ablation attempt, the patient had recurrent symptomatic palpitations associated with atrial tachycardias. Direct current cardioversion was needed twice within 1 month to restore sinus rhythm.

A decision then was made to attempt surgical ablation to interrupt isthmus conduction. The surgical ablation procedure was performed under general anesthesia with endotracheal intubation. A double-lumen endotracheal tube was 